\title{
Social structure affects the gut microbiota in honey bees: The physiological cost of precocious foraging
}

\author{
Duan Copeland ${ }^{1}$, Brendon Mott $^{2}$, and Kirk Anderson ${ }^{2}$ \\ ${ }^{1}$ University of Arizona \\ ${ }^{2}$ USDA-ARS Carl Hayden Bee Research Center
}

February 25, 2022

\begin{abstract}
Honey bees exhibit an elaborate social structure that corresponds with worker aging and division of labor. Young workers perform tasks inside the hive, while older workers forage outside the hive. Critical to colony fitness, the work force can respond rapidly to changes in the environment or colony demography and assume emergency tasks, resulting in young foragers or old nurses. We hypothesized that social structure affects the microbiome, more specifically, that behavioral task independent of age would generate differences in gut microbiota and host physiology. We used high throughput sequencing to track gut microbial succession, and measured gene expression and oxidative protein damage associated with behavioral task and age. We found that both age and behavioral task could explain differences in midgut and ileum microbiota, but host gene expression was best explained by an interaction of task and age. An extended nursing role in early life stabilized the ratio abundance of G. apicola and S. alvi in the ileum, while precocious foraging resulted in poor G. apicola establishment, nutrient deficient gene expression, and increased oxidative damage. Our results suggest that the physiological cost of early foraging is extreme, and highlight the progression of colony dwindling, a common but misunderstood process.
\end{abstract}

Title: Social structure affects the gut microbiota in honey bees: The physiological cost of precocious foraging Authors: Duan C .Copeland ${ }^{1,2^{*}}$, Brendon M. Mott ${ }^{1}$, and Kirk E. Anderson ${ }^{1 *}$

Author affiliations:

${ }^{1}$ USDA-ARS Carl Hayden Bee Research Center, 2000 E. Allen Rd, Tucson, AZ 85719, USA.

${ }^{2}$ Department of Microbiology, School of Animal \& Comparative Biomedical Sciences, University of Arizona, Tucson, AZ 85721, USA

*Corresponding authors. Email: Kirk.Anderson@usda.gov, Duan.Copeland@usda.gov

Author emails

Brendon.Mott@usda.gov

Mailing address: Carl Hayden Bee Research Center, USDA-ARS, 2000 E. Allen Rd., Tucson, AZ 85719. Phone: (520) 820-7186 Fax: (520) 670-6493.

Keywords: phenotypic plasticity, gut microbiota, precocious foragers, immunity, oxidative stress, vitellogenin, age-polyethism 


\section{ABSTRACT}

Honey bees exhibit an elaborate social structure that corresponds with worker aging and division of labor. Young workers perform tasks inside the hive, while older workers forage outside the hive. Critical to colony fitness, the work force can respond rapidly to changes in the environment or colony demography and assume emergency tasks, resulting in young foragers or old nurses. We hypothesized that social structure affects the microbiome, more specifically, that behavioral task independent of age would generate differences in gut microbiota and host physiology. We used high throughput sequencing to track gut microbial succession, and measured gene expression and oxidative protein damage associated with behavioral task and age. We found that both age and behavioral task could explain differences in midgut and ileum microbiota, but host gene expression was best explained by an interaction of task and age. An extended nursing role in early life stabilized the ratio abundance of $G$. apicola and $S$. alviin the gut, while precocious foraging resulted in poor G. apicolaestablishment, nutrient deficient gene expression, and increased oxidative damage. Metabolism associated with oxidative stress and the immune response is costly. While normal nurse development is a prerequisite for longevity, the metabolic trajectory of precocious foragers indicates early senescence. Our results suggest that the physiological cost of early foraging is extreme, and highlight the progression of colony dwindling, a common but poorly understood process.

\section{INTRODUCTION}

The ecological success of eusocial insects is attributed to an organized and efficient division of labor (Oster \& Wilson, 1978). Social insects solve complex problems with individual behaviors, resulting in emergent group properties (Hölldobler \& Wilson, 2008). The numbers of workers performing a particular task are optimized by feedback loops to efficiently collect, process, and distribute resources among colony members (Fewell, 2003). Individual workers transition among various tasks during their lifetime, and exhibit a broad range of phenotypic plasticity. More simply, colony demography is socially regulated (Z.-Y. Huang \& Robinson, 1996), allowing a proximate internal response to unpredictable external environments. Various worker tasks involve different physiological and behavioral demands, producing strong selection on social phenotypes. Social insects are well suited to the study of sociality and phenotypic plasticity because they represent a complex adaptive system or "superorganism" in which the functional parts can be manipulated and measured (Hölldobler \& Wilson, 2008).

Honey bees are highly social insects that live in complex societies consisting of one reproductive queen and thousands of facultatively sterile workers. While the queen spends a preponderance of her life laying eggs, workers build and maintain all aspects of the hive. Under normal conditions, adult workers display age polyethism-performing tasks within the hive for the first 2-3 weeks before transitioning to outside tasks (Seeley, 1982). Specifically, young adults function as "nurse bees" that feed growing larvae. Pupae are capped with wax and isolated until they emerge from their cell and become the next cohort of nurse bees. Meanwhile, near the end of their lifespan, older nurses transition into foragers that then procure nectar (carbohydrates), pollen (protein and lipids), propolis (antimicrobial plant resins), and water (Seeley, 1982). This delicate balance of age-based division of labor requires a high level of colony coordination and integration. Despite this well-established pattern, adult workers can decouple age from behavioral task in response to social cues from other workers and pollination environment (Z. Y. Huang \& Robinson, 1992). Thus, behavioral task is extremely plastic and nursing/foraging behaviors can be accelerated, slowed, or reversed (Robinson, 1992).

Phenotypic plasticity in honey bees workers is directly associated with the availability of nutrition and storage proteins, vitellogenin in particular (G. V. Amdam, Norberg, Hagen, \& Omholt, 2003). Vitellogenin (vg) is a phospholipoglyco-protein evolved to serve many functions; as an antimicrobial, antioxidant, and to produce brood food in the in nurse worker head (hypopharyngeal) glands (Gro V. Amdam, 2011; SiriChristine Seehuus, Norberg, Krekling, Fondrk, \& Amdam, 2007). In contrast, foragers switch to a diet of simple sugars to support the metabolism associated with flight. This transition is associated with reduced 
lipid stores (Toth \& Robinson, 2005), reduced Vg titers (Fluri, Lüscher, Wille, \& Gerig, 1982), decreased nutritional status (Ament, Corona, Pollock, \& Robinson, 2008), and differential gene expression (Ben-Shahar, Robichon, Sokolowski, \& Robinson, 2002). These are functional differences that likely contribute to being a successful forager; a decrease in body mass and a proportional increase in flight capacity (Vance, Williams, Elekonich, \& Roberts, 2009). However, leaving the relative safety of the hive is the riskiest time of an adult bee's life. A recent study documented that $40 \%$ of bees die during the pre-foraging stage of life, a time where bees perform exploratory and learning orientation flights (Prado et al., 2020). Bees that survive face a constant increase in extrinsic mortality risk per unit time that increases to $100 \%$ after 18 days of foraging activity (Dukas, 2008), yet only $\sim 20 \%$ of foragers will live past ten days of foraging (Visscher \& Dukas, 1997). Therefore, the age a worker initiates foraging has a strong impact on lifespan and group contribution.

Foraging also has direct consequences for intrinsic senescence, including increased sensitivity to physiological stressors (Remolina, Hafez, Robinson, \& Hughes, 2007) and a decrease in innate immune defenses (Gro V. Amdam et al., 2005; Gro V. Amdam, Simões, et al., 2004; Lourenço et al., 2019; Schmid, Brockmann, Pirk, Stanley, \& Tautz, 2008). Foragers also show an increased susceptibility to oxidative stress (S.-C. Seehuus, Norberg, Gimsa, Krekling, \& Amdam, 2006), including oxidative damage to the brain (Rueppell, Christine, Mulcrone, \& Groves, 2007), and the body (Hsieh \& Hsu, 2011). The accumulation of oxidative damage from reactive oxygen species (ROS) is proposed as the main cause of aging (Harman, 1956). Thus, a precocious transition to foraging is predicted to result in premature aging. Flight and the associated ROS accumulation from muscle usage and attrition may surpass the capacity for antioxidant enzymes to remove them. Indeed, the honey bee's innate antioxidant enzymes; various superoxide dismutases, catalase, and glutathione Stransferase, reach their greater expression in older workers (Corona, Hughes, Weaver, \& Robinson, 2005). While the physiology of behavioral plasticity and aging has been explored in honey bees, the role of the gut microbiome in this process is poorly known (Vonaesch, Anderson, \& Sansonetti, 2018).

Given the strong selection acting on social phenotypes, here we test their physiological range in association to the gut microbiome. The honey bee gut microbiota is remarkably consistent and dominated by five omnipresent, highly co-evolved phylotypes representing $>95 \%$ of bacterial cells (Kwong \& Moran, 2016; Martinson, Moy, \& Moran, 2012; Sabree, Hansen, \& Moran, 2012). Recent work has revealed a strong association of the microbiome with worker physiology including the expression of insulin like peptides and vitellogenin (Engel et al., 2016; Kešnerová et al., 2017; Maes, Rodrigues, Oliver, Mott, \& Anderson, 2016; Powell, Carver, Leonard, \& Moran, 2021; Raymann, Shaffer, \& Moran, 2017; Ricigliano et al., 2017; Zheng, Powell, Steele, Dietrich, \& Moran, 2017). Although nurses and foragers share a core microbiota (CorbyHarris, Maes, \& Anderson, 2014), microbial composition differs by behavioral task and may impact host physiology and health (Anderson et al., 2018). The worker gut microbiota is spatially organized, with the greatest abundance of bacteria found in the distal regions of the gut (Martinson et al., 2012). Specifically, the rectum comprises $>90 \%$ of the bacterial cells in honey bees and is an incredibly stable niche (Jones et al., 2018; Kapheim et al., 2015; Kešnerová et al., 2020; Ludvigsen, Andersen, Hjeljord, \& Rudi, 2020; Maes, Floyd, Mott, \& Anderson, 2021). Therefore, we chose to focus on the midgut and ileum as these niches are more likely to reveal the limits of phenotypic plasticity in relation to the microbiome. The midgut functions in digestion and absorption of food, but it is also considered a less stable substrate for bacterial colonization because midgut epithelial cells secrete an envelope called the peritrophic membrane in early adult life (Engel \& Moran, 2013b). The peritrophic membrane is continuously replaced as it is shed and serves to facilitate digestion, and as a protective barrier from damage by food particles and microbial invasion (Engel \& Moran, 2013b). At the pylorus, the Malpighian tubules excrete nitrogenous waste and electrolytes from the hemolymph presenting a nutrient-rich environment for microbes (Cintra-Socolowski, Nocelli, Roat, Silva-Zacarin, \& Malaspina, 2016; Cohen, Sawyer, Peterson, Dow, \& Fox, 2020). Midgut function including the production of peritrophic membrane decreases significantly in foragers (Harwood \& Amdam, 2021), but the impact on disease susceptibility and the gut microbiome are unknown.

It has been demonstrated in honey bees that individual worker behavior and physiology can be manipulated via the perturbation of social structure (Z.-Y. Huang \& Robinson, 1996). Here we ask whether such changes are reflected in the gut microbiome. To test if gut microbiota differences are associated with behavioral task or 
age, we created "single-cohort colonies" (SCC) comprised of bees that were all the same age (Robinson, Page, Strambi, \& Strambi, 1989). As a result, some proportion of the young bees in this colony will initiate foraging precociously to fill the missing ranks of normal-aged foragers. As the population ages, we assess differences in nurses and precocious foragers $(\mathrm{PF})$ of the same age, monitoring gene expression related to immunity and oxidative stress. Likewise, we assessed protein oxidation in the fat body resulting from precocious foraging. We hypothesized that precocious foragers would accumulate oxidative damage at a faster rate than same aged nurse bees. We test two hypotheses: (1) honey bees experience differences in the midgut and ileum microbiota that reflect age and behavioral task and (2) oxidative damage and gene expression reflect differences within and among age and behavioral task.

\section{METHODS}

\subsection{Colony Manipulations and Sampling}

In June 2019 at the USDA-ARS Carl Hayden Bee Research Center in Tucson Arizona, closed brood frames were sourced from 30 honey bee (Apis meliffera, linguistica) hives. Frames were incubated overnight $\left(30^{\circ} \mathrm{C}\right.$, $75 \%$ relative humidity, and $24 \mathrm{~h}$ dark cycle) and newly emerged adult workers were collected and combined into a mixed cohort to implement into experiment. We utilized a "single-cohort colony" (SCC) design, which was previously shown to uncouple behavioral task from chronological age (Robinson et al., 1989) (Figure 1A). To construct the two SCCs, newly emerged workers (4500 and 3500) were added to a small hive box, each containing a naturally mated queen, one frame with pollen and honey, and one frame with eggs and open brood. Bees assigned to each SCC were less than 24hours old and differentiated into separate behavioral tasks, i.e., nurses and atypically, precocious (young) foragers (PFs). Additionally, a marked cohort (MC) with 4100 newly emerged workers was constructed to serve as a control for sampling normal ontogeny (Figure 1A). Newly emerged workers were marked with paint on their thorax and transferred into a healthy double-deep colony free from visible signs of disease. On day 6 of the experiment, SCC PFs we observed with corbicular pollen loads were marked with paint on their thorax.

At the peak of foraging activity in the summer, a workers lifespan is approximately 30 days (Fluri et al., 1982). Over the course of the experiment, we sampled foragers and nurses from the SCCs at 7, 13, and 19-days old (Figure 1B). By design, SCC nurses and foragers performed the same behavioral tasks for the duration of the experiment. Nurses were identified by observing the brood nest and sampling bees that spent 3 seconds with their head in a cell containing brood. Part way through the experiment, we replaced the brood frame in the SCC's to ensure no newly emerged workers replace the current nurses. For the MC sampling, we sampled age-right nurses at 7 and 13-days old and age-right foragers at 27-days based on well-established honey bee worker ontogeny (Seeley, 1982). Thus all samples could be categorized as normal (age-right) or atypical (PFs and overage nurses) ontogeny (Figure 1C). Sampled bees were collected with sterile soft forceps, snap frozen with dry ice, and stored in $-80^{\circ} \mathrm{C}$ for processing.

Worker dissections occurred under sterile conditions. The sting was discarded and the fore and hindguts were removed from the abdomen. Gut tissues were dissected in $70 \% \mathrm{EtOH}$ to wash and separate the midgut and ileum before being added to a bead-beating tubes with $0.2 \mathrm{~g}$ of $0.1-\mathrm{mm}$ silica beads and $600 \mu \mathrm{L}$ of $1 \mathrm{X}$ TE buffer. The abdominal fat body and attached dorsal sclerites were retained in similar bead beating tubes as a single unit for gene expression and protein oxidation (carbonyl) assay.

\subsection{DNA extraction and qPCR}

In preparation for DNA/RNA extractions, samples were bead-beaten for 2 min at 30-s intervals and centrifuged to recover the supernatant. Midgut and ileum DNA were extracted according to Thermo Scientific GeneJET Genomic DNA Purification Kit manufacturer's instructions. Fat body supernatant was split 300 $\mu \mathrm{L}$ for the carbonyl assay and $300 \mu \mathrm{L}$ for RNA extraction with Thermo Scientific GeneJET RNA Purification 
Kit according to manufacturer's instructions. The extracted fat body RNA was converted into cDNA with Thermo Scientific RevertAid First Strand cDNA Synthesis Kit according to manufacturer's instructions.

We quantified total bacterial abundance for the midgut and ileum with a real-time PCR (qPCR) assay of bacterial 16S and fungal 18S rRNA gene copies (C. M. Liu, Aziz, et al., 2012; C. M. Liu, Kachur, et al., 2012). This assay provides significantly broader coverage than previously reported universal quantification assays. The bacterial $16 \mathrm{~S}$ gene template was amplified using forward primer 27F (5'-AGAGTTTGATCCCTCAG -3 ') and reverse primer 1522R (5'- AAGGAGGTGATCCAGCCGCA -3'). The fungal 18S gene template was amplified using forward primer PanFungal_18S_F (5'-GGRAAACTCACCAGGTCCAG -3') and reverse primer PanFungal_18S_R (5'-GSWCTATCCCCAKCACGA-3'). Invitrogen's pCR2.1 TOPO was used to produce plasmid vectors, which were then transformed into DH5 $\alpha$ cells. Successfully transformed colonies were selected and grown overnight in broth. Plasmid DNA was purified using the Thermo Scientific GeneJET Plasmid Miniprep Kit according to manufacturer's instructions. The purified plasmid cells were measured using an Implen nanophotometer P300 to calculate 10-fold serial dilutions as the standards for qPCR quantification.

Quantitative PCRs for 16S and 18S were carried out in triplicate on a BioRad CFX96 thermocycler in 12 $\mu \mathrm{L}$ reactions containing $6 \mu \mathrm{L}$ of New England Biolabs - Lunaß Universal Probe qPCR Master Mix, 0.5 $\mu \mathrm{L}$ forward primer, $0.5 \mu \mathrm{L}$ reverse primer, $3 \mu \mathrm{L}$ of $\mathrm{H}_{2} \mathrm{O}$ and $2 \mu \mathrm{L}$ of DNA template. The cycling conditions were $95{ }^{\circ} \mathrm{C}$ for $3 \mathrm{~min}$ followed by 40 cycles of $95{ }^{\circ} \mathrm{C}$ for $10 \mathrm{~s}$ and $60{ }^{\circ} \mathrm{C}$ for $60 \mathrm{~s}$. The qPCR results were expressed as the total number of $16 \mathrm{~S}$ and $18 \mathrm{~S}$ rRNA gene copies per DNA extraction (100 $\mu \mathrm{L}$ volume elution).

\subsection{Immune Gene Expression}

The fat body is a main metabolic tissue of the honey bee and is functionally analogous to vertebrate liver or adipose tissue (Y. Liu et al., 2009). Comparisons of fat body gene expression can relay information on immunocompetence and overall health. Fat body immune and oxidative stress gene expression was quantified for vitellogenin $(v g)$, apidaecin, catalase, copper-zinc superoxide dismutase (CuZnSOD), down syndrome cell adhesion molecule (DSCAM ), glutathione S-transferase-1 (GST-1 ), hymenoptaecin , manganese superoxide dismutase $(M n S O D)$, major royal jelly protein 2 (mrjp2), and prophenoloxidase (PPO).

Quantitative PCR reactions for immune gene expression were performed in triplicate as follows: initial denaturation at $95{ }^{\circ} \mathrm{C}$ for 5 minutes; 40 cycles with denaturation at $95{ }^{\circ} \mathrm{C}$ for $15 \mathrm{~s}$; and a primer-pair-specific annealing and extension temperature for 30 seconds (Table S1). To confirm the absence of contaminating genomic DNA and primer dimers in the $\mathrm{qPCR}$ assay, we monitored amplification and melting curves. Relative gene expression was determined based on standardized Ct values ( $\Delta \mathrm{Ct}$ ) (Livak \& Schmittgen, 2001) using actin as a reference gene. Actin is constitutively expressed in different honey bee tissues and has been previously established as an effective control for measuring gene expression in adult workers (Evans et al., 2013).

\subsection{Carbonyl Assay}

To measure protein damaged by oxidative stress, we quantified the accumulation of protein carbonyl groups (Reznick \& Packer, 1994). The method for measuring carbonyl content in honey bees has been previously established (Anderson et al., 2018; Hsieh \& Hsu, 2011; Williams, Roberts, \& Elekonich, 2008). To determine carbonyl content of fat body homogenates, we used Protein Carbonyl Content Assay Kit (MAK094; SigmaAldrich). Briefly, samples were treated with a $10 \mathrm{mg} / \mathrm{ml}$ streptozocin solution and incubated for $15 \mathrm{~min}$ to precipitate nucleic acids. Keeping the supernatant, 2,4-dinitrophenylhydrazones (DNPH) was added to samples to form stable dinitrophnyl hydrozone adducts. Derivatized proteins were precipitated with trichloroacetic acid and were followed by three successive ice-cold acetone washes. Samples were resuspended in $100 \mu \mathrm{l}$ of $6 \mathrm{M}$ guanidine $(\mathrm{pH} 2.3)$. The total protein concentration of each sample was measured using a Pierce ${ }^{\mathrm{TM}}$ BCA Protein Assay Kit (Smith et al., 1985). Protein oxidation was expressed as nanomoles of carbonyl groups per mg of protein. 


\subsection{S rRNA gene community analysis}

16S rRNA gene sequences were processed using MOTHUR v.1.44.3 (Schloss et al., 2009). Forward and reverse reads were joined using the make.contigs command. After the reads were joined, the first and last five nucleotides were removed using the SED command in UNIX. Sequences were screened to remove ambiguous bases, using the screen.seqs command. Unique sequences were generated using the unique.seqs command. A count file containing group information was generated using the count.seqs command. Sequences were aligned to Silva SSUREF database (v102) using the align.seqs command. Sequences were filtered to remove overhands at both ends and gaps using filter.seqs. The unique.seqs command was ran again to remove new redundancies from filtering. A precluster step using pre.cluster was performed. Chimeras were removed using chimera.uchime command (Edgar, Haas, Clemente, Quince, \& Knight, 2011). Sequences were classified with a bayesian classifier using the Silva database using classify.seqs command. Sequences that were not bacterial origin were removed using the remove.seqs command. All unique sequences with one or two members (single/doubletons) were removed using the AWK command in UNIX. A distance matrix was constructed for the aligned sequences using the dist.seqs command. Sequences were classified at the unique level with the Ribosomal Database Project (RDP) Naive Bayesian Classifier (Wang, Garrity, Tiedje, \& Cole, 2007) using a manually constructed training set containing sequences sourced from the greengenes $16 \mathrm{~S}$ rRNA database (version gg_13_5_99 accessed May 2013), the RDP version 9 training set, and all full-length honeybee-associated gut microbiota on NCBI (accessed July 2013). Operational taxonomic units (OTUs) were generated at the $97 \%$ species using the cluster command. Representative sequences for each OTU were generated using the get.oturep command. To further confirm taxonomy, resulting representative sequences were subject to a BLAST query using the NCBI nucleotide database.

\subsection{Statistical Analysis}

We evaluated our microbial datasets as both relative and absolute abundance for downstream analyses. To examine the effect of community size, the top ten OTUs and a sum of remaining OTUs were used for downstream analysis. It should be noted that OTU 1-10 accounted for $95 \%$ of all sequences, the 11th group consisted of 'Other' ( $\Sigma$ OTUs 11-1230) accounted for the remaining $5 \%$. OTUs were normalized by $16 \mathrm{~S}$ rRNA gene copy number via ribosomal RNA operons $(r r n)$ database (Stoddard, Smith, Hein, Roller, \& Schmidt, 2015) and total bacterial 16S rRNA gene copies from qPCR prior to analysis. In this case, qPCR-normalized abundance is extrapolated from relative abundance of amplicons, so remains compositional. To allow the use of parametric multivariate analyses (Pearson, 1897), we converted the qPCR-normalized bacterial abundances to ratios among all OTUs (Gloor \& Reid, 2016) using the software CoDaPack's centered log ratio (CLR) transformation (Comas \& Thió-Henestrosa, 2011). After conversion, nearly all OTUs followed normal distributions. A two-way MANOVA was performed on log-converted relative abundances which allows for comparing taxa between dependent (OTU 1-11) and independent (age, behavioral task, and age*behavioral task) variables. As an additional measure, we used Pillai's Trace test statistics which are robust in terms of violations of multivariate normality and homogeneity of covariance. To account for multiple comparisons, a False Discovery Rate (FDR) was conducted. We also performed principle component analysis (PCA) on CLR scores from OTUs 1-11, plotting the relationship of bacterial community composition with behavioral task and age-associated succession. To determine differences in absolute abundance of the microbial communities, we used Wilcoxon rank sum tests corrected for multiple comparison with Steel-Dwass. Absolute abundance was used to determine correlations between OTUs using Spearman's $\rho$ which was further corrected by FDR for multiple comparisons. MicrobiomeAnalyst web interface was used to analyze bacterial community diversity and composition (Chong, Liu, Zhou, \& Xia, 2020). Alpha diversity metrics, Observed and Shannon were used to measure the richness and evenness using Mann-Whitney or Kruskal-Wallis statistical tests where appropriate. Beta diversity was used to compare the microbial communities with Bray-Curtis dissimilarity between each sample pair. The ordination was plot with non-metric multidimensional scaling (NMDS) using PERMANOVA as the statistical test for significance. 
We evaluated bacterial and fungal copy numbers by sample type (age and task combined, i.e., 7-day nurse and 7-day forager) using one-way ANOVA with Tukey's HSD post-hoc. Gene expression were log 10 transformed to normalize variation and analyzed by sample type using TWO WAY one-way ANOVA with Tukey's HSD post-hoc. PCAs of normalized gene expression was used to plot the relationship of immunity and oxidative stress with behavioral task and age. Carbonyl content significance was evaluated by sample type using TWO WAY one-way ANOVA with Tukey's HSD post-hoc. In order to verify MC as a control following normal ontogeny we compared SCC age-right nurse microbiota and gene expression with the MC using Wilcoxon 2-sample t-test with FDR corrections. Multivariate analyses were conducted on OTUs with gene expression and carbonyl contents using Spearman's $\rho$ to find significant correlations after correcting for multiple comparisons with an FDR. All analyses were conducted in JMP_ v14.3.0 (JMP_ 1989-2007) and/or SAS_ v9.4 (Institute, 2015). We considered values of $P<0.05$ statistically significant.

\section{RESULTS}

\section{$3.116 \mathrm{~S}$ rRNA gene sequencing}

Next-generation sequencing returned 11.5 million quality trimmed reads (455 bp assembled) across 292 libraries. The worker midguts represented about 4.4 million reads averaging $31 \mathrm{~K}$ per library. The worker ileums represented about 7.1 million read averaging $49 \mathrm{~K}$ per library. A total of 1230 OTUs were resolved at $97 \%$ similarity. The top 10 OTUs and a 11th group consisting of 'Other' ( $\Sigma$ OTUs 11-1230), represented $95 \%$ and $5 \%$ of the total reads, respectively. The most abundant OTUs according to raw amplicon read totals were Gilliamella apicola (23.1\%),Snodgrassella alvi (17.6\%), Frischella perrara (13.2\%), Apilactobacillus apis (Firm5-1, 12.7\%),Apilactobacillus kunkeei (7.3\%), Apilactobacillus Firm4 (7.1\%), Apilactobacillus Firm5 (Firm5-2, 7.1\%),Bifidobacterium sp. (3.8\%), Fructobacillus fructosus (2.5\%), and an Enterobacter sp. (0.8\%) (Figure 2A). This is largely consistent with previously described worker microbiota analysis (Kwong \& Moran, 2016). Our analyses clustered ApilactobacillusFirm-5 as two distinct clades, Apilactobacillus apis("Firm51") which favors the ileum and a second ("Firm5-2") cluster that was more abundant the midgut (Figure 2A). Firm5-2 BLAST hits gave sequences identities to Lactobacillus panisapium, Lactobacillus kimbladii, and Lactobacillus helsingborgensis .

Our MC and SCC age-right nurses gut microbiota were compared and did not differ statistically (Table S2). Therefore, we added MC nurses to 7 and 13-day old SCC nurses for all downstream statistics.

\subsection{Microbiota associations with age and task}

The two-way MANOVA performed on midguts and ileums revealed significant variation due to age and behavioral task, but not as an interaction factor (Table 1). In the midgut, the MANOVA revealed significance for eight of the OTUs analyzed. The independent variables (IV) of age (F value $3.72, \operatorname{Pr}>\mathrm{F}=0.0001)$ and behavioral task (F Value 5.56, $\mathrm{Pr}>\mathrm{F}=0.0001$ ) were significant for six OTU each. Specifically, G. apicola, was more abundant in age-right nurses versus their same age PFs. G. apicola also increased with age; in 27day old age-right foragers and 19-day overage nurses had the largest proportions and the largest microbiotas based on 16S rRNA gene copies (Figure 3A). S. alvi and Enterobacter sp. increased with age regardless of behavioral task, while A. kunkeei and $F$. fructosus showed larger relative abundances in nurses rather

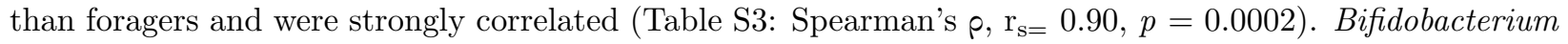
$s p$. , Firm4, and Firm5-2 were highly correlated across all samples (Table S3: Spearman's $\rho, \mathrm{r}_{\mathrm{s}=} 0.90, p=$ 0.0002), but had higher relative abundance in PFs versus age-right nurses as well as increasing with age. PCA on CLR adjusted midgut microbiota shows tight grouping for behavioral task, with $31.6 \%$ explanation for the first component and $15.1 \%$ for the $2^{\text {nd }}$ component. Grouping is also consistent on microbial based age-association (Figure S1). Patterns predicted by MANOVA are represented in the PCA withA. kunkeei and $F$. fructosus being more associated with nurses and the highly correlated OTUs, Bifidobacterium sp , Firm4, and Firm5-2 found in the guts of foragers. 
A visual inspection of the ileum's relative abundances shows remarkable stability across age and behavioral task compared to the midgut (Figure 2A). The size of the ileum microbiota was mostly consistent across treatment groups (Figure 3A). Nevertheless, the two-way MANOVA revealed significant variation due to age ( $\mathrm{F}$ value 3.17, $\operatorname{Pr}>\mathrm{F}=0.0001$ ) and behavioral task ( $\mathrm{F}$ value $4.74, \operatorname{Pr}>\mathrm{F}=0.0001$ ). There were five OTU significant in the model, five of which were best explained by age and four by behavioral task. The bacteria $G$. apicola, S. alvi, Firm4, and Firm5-2 were explained by both factors in the model. Firm4 and Firm5-2 were also very strongly correlated across all samples (Table S4: Spearman's $\rho, \mathrm{r}_{\mathrm{s}}=0.82, p=0.0006$ ) A PCA on CLR adjusted ileum microbiota shows overlap for behavioral task, with $23.7 \%$ for the first component and $19.5 \%$ for the $2^{\text {nd }}$ component. Age-associated grouping is also consistent with the MANOVA with less overt differences in the ileum relative to the midgut (Figure S2).

Wilcoxon on absolute abundance were largely in congruence with the significant results of the two-way MANOVA (Table S5 and S6). There was also uniformity with gut microbiota size; 27-day age-right foragers had significantly more cell counts for many of the top OTUs in the midgut (Figure 3A). 16S rRNA gene copies increased significantly with age in the midgut but the ileum microbiota remained the same size over time. The fungal loads were more similar between sample types and tissues but bifurcated by age and task in the midguts; the oldest nurses and 27-day foragers had the greatest fungal loads (Figure 3B). The alpha diversity metric for richness was significant for age and sample type $(p$-value $<0.0001)$, while beta diversity was significant for task only ([PERMANOVA] F-value: 5.3629; R-squared: $0.01991 ; p$-value $<0.02$ ) (Figure S5).

\subsection{Gene expression associations}

Two-way ANOVA found an interaction effect between age and behavioral task for all immune gene expression in the fat body, except for the AMPs apidaecin and hymenoptaecin (Table S7). Nonetheless, both AMPs were significant for age or behavioral task independently.

Two PCAs reveal patterns in immune gene expression by behavioral task and/or age (Figure 4). The first principal component (29.1\%) maximizes the variance of immune gene expression, with gene vectors along the horizontal explained more by behavioral task (Figure 4A). In contrast, genes that are parallel to the second component (20.1\%) are more closely associated with age (Figure 4B). Significant differences between sample types dichotomize by behavioral task. Vitellogenin is highly expressed in all age nurses and downregulated in age-matched and age-right foragers (Figure 5A). Hymenoptaecin and catalase had increased expression in foragers (Figure 5B-C). Apidaecin, CuZnSOD, and GST-1 followed age-associated gene expression patterns with age-right 27-day foragers having the highest transcript levels (Figure 5F-H). DSCAM and MnSOD had expression patterns that were affected by task and age (Figure 5D-E). DSCAM was expressed higher in age-matched PFs versus nurses but decreased in both with age. MnSOD was highest in age-right nurses compared to age-matched foragers, and decreased as the PF aged. MRJP2 was depressed in older nurses but also appears to increase with age while PPO was expressed at the same levels across all sample types (Figure S6).

Midgut tissue showed the most variation in microbial composition (Figure 2A) and size (Figure 3A). Therefore, we looked at correlations between the midgut bacterial absolute abundance with fat body gene expression to investigate potential relationships between the aging midgut and overall immune health (Table S8). In PFs only, we found a positive correlation of CuZnSOD with $F$. fructosus $\left(\mathrm{r}_{\mathrm{s}}=0.42, p<0.008\right)$. There were no significant correlations in nurses, but when considering all samples, including age-right 27-day foragers, we found many positive relationships with CuZnSOD; G. apicola $\left(\mathrm{r}_{\mathrm{s}}=0.32, p<0.0001\right)$, Firm5-1 $\left(\mathrm{r}_{\mathrm{s}}=0.29, p<0.002\right), F$. fructosus $\left(\mathrm{r}_{\mathrm{s}}=0.30, p<0.002\right)$, A. kunkeei $\left(\mathrm{r}_{\mathrm{s}}=0.29, p<0.002\right)$, S. alvi $\left(\mathrm{r}_{\mathrm{s}}\right.$ $=0.27, p<0.005)$, and Bifidobacterium $\left(\mathrm{r}_{\mathrm{s}}=0.24, p<0.01\right)$. Hymenoptaecin gene expression correlated positively with Bifidobacterium $\left(\mathrm{r}_{\mathrm{s}}=0.2, p<0.006\right)$ and Firm5-2 $\left(\mathrm{r}_{\mathrm{s}}=0.23, p<0.02\right)$. There were two negative correlations found with all samples, MnSOD with Firm5-2 $\left(\mathrm{r}_{\mathrm{s}}=-0.23, p<0.02\right)$ and DSCAM with F. fructosus $\left(\mathrm{r}_{\mathrm{s}}=-0.32, p<0.05\right)$. 


\subsection{Carbonyl contents of abdomen}

Oxidative damage in the abdomen was measured by carbonyl assay of the fat body and attached abdominal sclerites. Foragers had accumulated more oxidized proteins than age-matched nurses, a finding that became statistically meaningful after 19-days (Figure 6). 19-day foragers and nurses had also accrued significantly more carbonylation than age-right 27-day foragers. As predicted Carbonyl contents decreased with increased $\mathrm{Vg}$ expression $\left(\mathrm{r}_{\mathrm{s}}=-0.28 \mathrm{p}<0.0006\right)$. To consider whether fat body gene expression or midgut bacterial absolute abundance had a relationship with carbonyl content accumulation we ran a Spearman's correlation analysis (Table S8). Considering all samples, carbonyl contents were negatively associated with the abundance of $G$. apicola $\left(\mathrm{r}_{\mathrm{s}}=-0.26, p<0.0071\right)$. The abundance of $S$. alvi and G. apicola was positively correlated in workers with natural ontogeny (nurses; $\mathrm{r}_{\mathrm{s}}=0.55, \mathrm{p}<0.01$ ), but showed no relationship in precocious foragers.

\section{DISCUSSION}

Our results reveal that the manipulation of social structure affects the development of the gut microbiome and associated physiology. Worker midgut and ileum microbiotas differed in composition and abundance by both age and behavioral task (Figure 2 and Table 1), as did immune and oxidative stress gene expression (Figure 5). Based on our chosen genes, host physiology was best explained by an interaction of age and task, with the greatest variation explained by behavioral task. This result is likely a reflection of differential nutrition and Vg titers associated with both age and task performance (Fig. 5). Beyond its role in nutrition, $\mathrm{Vg}$ is a potent antioxidant. We found that precocious foragers (PFs) with low Vg expression incur oxidative damage via the accumulation of carbonyl contents in the hemocoel at a significantly greater rate than both age-matched nurses and age-right (27-day) foragers (Figure 6). Young bees transition to foraging faster when there is limited social contact with older bees (Z.-Y. Huang \& Robinson, 1996; Pankiw, 2004). This can occur in response to various biotic (predators, pathogens) or abiotic (pesticides, anthropogenic factors) pressures. The nutrient deficient physiology of PFs may be poorly suited for tasks outside the hive (Vance et al., 2009) and evidence suggest that PF individual risk of death increases relative to older foragers (Prado et al., 2020). Precocious foraging is also less productive (Chang, Barron, \& Cheng, 2015), factors that conspire to accelerate colony loss (Perry, Søvik, Myerscough, \& Barron, 2015).

Associated with the control of complex social behaviors in honey bees, vitellogenin ( $\mathrm{Vg}$ ) is a major reproductive protein that functions as a regulatory gene in workers (Gro V. Amdam, Norberg, Fondrk, \& Page, 2004). Consistent with this result, we found that Vg expression was differentially expressed between 7-day old nurses and PFs of the same age (Figure 5A). High titers of circulating Vg provide several benefits to young bees; immunity, oxidative stress resistance, increased longevity, and suppression of foraging behaviors (Gro V. Amdam, 2011; Gro V. Amdam et al., 2005; Marco Antonio, Guidugli-Lazzarini, Do Nascimento, Simões, \& Hartfelder, 2008; Nelson, Ihle, Fondrk, Page, \& Amdam, 2007; S.-C. Seehuus et al., 2006). Because $\mathrm{Vg}$ expression is tightly coupled with division of labor, we can confirm that our experimental design was successful in distinguishing the general physiology associated with nursing and foraging.

The midgut microbiota varied in composition based on age and behavioral task. Previous studies have suggested that the nurse midgut is inhospitable to microbial colonization because of the continual shedding of the peritrophic membrane (Harwood \& Amdam, 2021). Here we report the aging midgut as a potential niche for microbial invasion based on aging gut physiology and forager gene expression (Figure 3A, 5). Recently, it was shown that the peritrophic membrane is absent or greatly reduced in foragers (Harwood \& Amdam, 2021), which may leave the tissue vulnerable to microbial opportunism. We saw a massive increase in midgut microbiome size in 27-day-old foragers (Figure S1). Gilliamella apicolaabundance in the midgut was greatest in age-matched nurses vs. foragers and comprised nearly half of bacterial cells in 27-day-old foragers. G. apicola often dominates the midgut (Ludvigsen et al., 2015), but is often lacking in the ileums of young nurse workers, becoming better established at middle age (Anderson \& Ricigliano, 2017). G. apicola strains have varying capabilities to degrade pollen cell wall components (Engel \& Moran, 2013a), metabolize toxic monosaccharides (Zheng et al., 2016), and encode battlefield genes such as type VI secretion systems (Steele, Kwong, Whiteley, \& Moran, 2017). Because we clustered OTU's at 97\% sequence similarity, G. 
apicola strain taxonomic refinement is lost and more research is required to unlock their individual genomic potential (Anderson \& Ricigliano, 2017). G. apicola abundance in the ileum showed the strongest relationship with task, establishing more efficiently in nurses than precocious foragers. Tasks within the hive may increase the chance of compatible G. apicola establishment, or fortify its establishment via other mechanisms.

The succession of gut bacteria in honey bee workers is poorly known, and is typically considered in terms of both task and age. The G. apicola / S. alvi relationship is one primary metric of a healthy gut microbiome. For the adult worker, $S$. alvi is considered a keystone species in the ileum/pylorus, interfacing with host epithelium and creating a biofilm with G. apicola and Lactobacillusfirm5 (Martinson et al., 2012). S. alvi protects the host from opportunism (Maes et al., 2016), while producing nutrients to support other gut bacteria (Kwong \& Moran, 2016). Both G. apicola andS. alvi increase with age and stabilize in ratio abundance in the midgut and ileum, succession apparently accelerated and reinforced by an extended nursing role in early life (Tables S5, S6). With natural ontogeny, variation of the three major ileum bacteria was minimized at 27 days of age relative to younger bees, suggesting a long-term adult refinement of ileum microbiome structure. In stark contrast, the midgut microbiota of the oldest workers was an order of magnitude larger than younger bees including significantly more (non-core) bacterial diversity, suggesting opportunism (Fig. 3). The different successional patterns documented between midgut and ileum might suggest an important function of the gut microbiome in mitigating gut opportunism and dysbiosis. Following the decreased production of midgut peritrophic membrane, bacteria populate the midgut, a process that may rely on early bacterial succession and strong establishment of core ileum species. This hypothesis is supported by the significant negative association of $G$. apicola abundance with the abundance of non-core "other" diversity in the midgut of 27 -day-old bees $(\mathrm{Rsq}=0.42, \mathrm{~F}=10.3, \mathrm{p}<0.006)$. Both $G$. apicola and Enterobacteriales increase with age in the hindgut and are positively associated with fungal abundance suggesting opportunism associated with senescence (Maes et al. 2020).

Although not considered part of the core gut microbiome, Enterobacteriales have been repeatedly discovered in the honey bee gut (Corby-Harris et al., 2014; Dalenberg, Maes, Mott, Anderson, \& Spivak, 2020; Kešnerová et al., 2020; Maes et al., 2021), and here we found that they increase with age in both the midgut and ileum regardless of behavioral task. Many genera belonging to Enterobacteriales have significant impacts on human health and recently, a strain ofSerratia marcescens was shown to be an underreported pathogen of honey bees (Burritt et al., 2016; Raymann, Coon, Shaffer, Salisbury, \& Moran, 2019). Enterobacteriales and other lesser understood genera are omnipresent in the guts and hives of honey bees and require more investigation in relation to the aging midgut.

Apilactobacillus kunkeei and Fructobacillus fructosus were highly intercorrelated and more abundant in nurses than foragers. A. kunkeei is often considered a hive and foregut-inhabiting bacteria that favors oxygen and high fructose niches but is also found in the hindgut in low numbers. F. fructosus is often ignored as a transient member of the microbiota, but recently it was discovered that it can utilize lignin, another component of pollen (Rokop, Horton, \& Newton, 2015). Coculture assays demonstrate that A. kunkeei andF. fructosus support the growth of other honey bee symbionts considered "core hindgut bacteria" (Rokop et al., 2015). Together, this suggests that so-called transient microbes may have a co-evolved functional roles within the honey bee gut as more ubiquitous microbial members. Core gut microbiota Firm4, Firm5-2, and Bifidobacterium $s p$. were found together and explained by age and behavioral task because they were more abundant in foragers relative to nurses. Our sequences clustered Firm5 as two distinct clusters with Firm5-1 most abundant in the ileum. This is supported by previous research indicating there are many adapted strains of Firm5 throughout the honey bee gut, some more proximately available to takeover niches during age-based succession (Anderson, Rodrigues, Mott, Maes, \& Corby-Harris, 2016).

Overall we detected gene expression patterns explained primarily by the interaction of age and task (Table S7). Antimicrobial peptides (AMPs) are expressed as part of the innate immune system of the honey bee (reviewed in Alberoni et al. , 2016). Explained primarily by task, we found high levels of hymenoptaecin in all ages of foragers and strong upregulation of apidaecin in 27-day foragers. This pattern is supported by studies that show foragers express genes encoding AMPs greater than nurses (Vannette, Mohamed, \& John- 
son, 2015). Similar to our findings, honey bees inoculated with gut microbiota or mono-colonized withS. alvi , upregulated apidaecin and hymenoptaecin constitutively in the fat body (Kwong, Mancenido, \& Moran, 2017). The core microbiota tends to have increased tolerance for host AMPs compared to allochthonous microorganisms (Kwong et al., 2017), therefore it's advantageous to constitutively express AMPs as a prophylactic measure given that foragers are exposed to more pathogen pressure outside the hive. Younger foragers also expressed DSCAM higher than age-matched nurses, with an age-associated decline by 19-days (Figure 5D). InDrosophila, DSCAM is a highly diverse Ig-superfamily receptor that may affect phagocytic uptake of bacteria by host hemocytes (Watson et al., 2005). The number of honey bee hemocytes decrease in relation to age and behavioral task (Gro V. Amdam et al., 2005; Gro V. Amdam, Simões, et al., 2004; Schmid et al., 2008). Specifically, foragers had decreased hemocyte counts in the hemolymph and a higher number of pycnotic cells than nurse bees. The honey bee DSCAM gene has the potential to generate as many as 12,000 splice variants which may allow them to target specific pathogens (Graveley et al., 2004). The expression of DSCAM shows a strong negative association with Vg expression (Table S8), suggesting it is not governed by nutritional state. Taken together, higher DSCAM expression in nutrient depleted foragers may serve to increase efficiency of the decreased number of hemocytes.

We also considered the effects of oxidative stress in relation to aging and behavioral task. Oxidative stress produced by intensive foraging flights is likely mitigated by host enzyme expression within the limits of host physiology. We found that CuZnSOD increased with age, MnSOD was higher in nurses and decreased with age, and catalase was highest in precocious foragers. CuZnSOD and MnSOD detoxify the free radical superoxide $\left(\mathrm{O}_{2} \cdot-\right)$ into the less reactive hydrogen peroxide $\left(\mathrm{H}_{2} \mathrm{O}_{2}\right)$, which is then processed by catalase into water and oxygen (Lei et al., 2016). Mitochondrial activity during aerobic respiration (flight) is the main cause of ROS generation, which tends to generate more $\mathrm{H}_{2} \mathrm{O}_{2}$. Fat body respiration is greater in nurses due to the continuous production of substances (e.g. Vitellogenin) needed to sustain brood rearing. Foragers experience ROS production in the flight muscles of the thorax that would circulate throughout the hemolymph. A previous study found that abdominal $\mathrm{H}_{2} \mathrm{O}_{2}$ levels were elevated in forager flight muscles as a possible result of increased mitochondria density (Cervoni et al., 2017). Foragers also have decreased abdominal lipid stores (Toth \& Robinson, 2005), less developed fat body (Ament et al., 2008; Wilson-Rich, Dres, \& Starks, 2008), and a decrease in Vg expression compared to nurses (S.-C. Seehuus et al., 2006). While young bees have generally more resistance to oxidative stress, foragers incur a gradual accumulation of tissue damage reflecting age-associated declines in the efficiency and degradation of ROS (Williams et al., 2008). We showed that 19-day foragers that had been foraging since at least 6-days old, had a high level of fat body protein carbonylation relative to age-matched nurses and age-right 27-day foragers (Figure 6 ). The age-right 27-day foragers had the highest oxidative stress gene expression, which could explain their low levels of protein carbonylation. These were the bees that remained nurses the longest and most recently transitioned to foraging (see Vg expression relative to 7-13-19-day foragers Figure 5A). The 19-day PFs antioxidant capacity may have reached its physiological limit. There were some significant correlations between CuZnSOD expression levels and bacterial cell abundance in the midgut, including G. apicola . Paradoxically, ROS can have positive effects such as acting in redox signaling pathways (Lei et al., 2016) or modulating the microbiota (Engel \& Moran, 2013b). Taken together, these findings warrant further investigation into host-gut microbe interactions focused on the honey bee midgut.

\section{CONCLUSION}

Honey bees are challenged continuously by environmental and agricultural factors that alter colony demography. Our results demonstrate that the social structure of honeybee colonies affects composition of the gut microbiota. Behavioral differences are associated with internal damage from reactive oxygen species, and changes in gene expression that rely on nutritional state and task. Precocious foragers accrue oxidative damage as a result of intense foraging activity experienced by a physiologically deficient adult worker. The colony-level cost of precocious foraging is extreme and one of many altruistic qualities inherent to social insects. The physiological demands of foraging are best met by older workers that have transitioned to foraging following extended development within the hive. In a healthy colony, the characteristic transition from nurse to forager results in less physiological stress. Consistent with this hypothesis, the ratio abundance of 
keystone ileum species $S$. alvi and G. apicolais refined with an extended nursing period, setting the stage for long-lived foragers. As workers age, we propose that the midgut becomes a niche for rapid microbial colonization, with consequences for both individual and colony survival.

\section{ACKNOWLEDGEMENTS}

The study was supported by the ARS-USDA, Carl Hayden Bee Research Center, CRIS project plan Anderson 2022-21000-021-00D. We thank Patrick Maes for technical and bioinformatics support. The ARS is an equal opportunity employer and provider.

\section{CONFLICT OF INTEREST}

The authors declare no conflict of interest.

\section{AUTHOR CONTRIBUTIONS}

Experimental design by D.C.C., B.M.M. and K.E.A. D.C.C. performed laboratory work with the input of K.E.A. and B.M.M. D.C.C. and K.E.A. analyzed the data and wrote the manuscript, and all authors commented on the manuscript.

\section{REFERENCES}

Alberoni, D., Gaggìa, F., Baffoni, L., \& Di Gioia, D. (2016). Beneficial microorganisms for honey bees: problems and progresses.Applied Microbiology and Biotechnology , 100 (22), 9469-9482. doi: 10.1007/s00253016-7870-4

Amdam, G. V., Norberg, K., Hagen, A., \& Omholt, S. W. (2003). Social exploitation of vitellogenin. Proceedings of the National Academy of Sciences , 100 (4), 1799-1802. doi: 10.1073/pnas.0333979100

Amdam, Gro V. (2011). Social context, stress, and plasticity of aging.Aging Cell , 10 (1), 18-27. doi: 10.1111/j.1474-9726.2010.00647.x

Amdam, Gro V., Aase, A. L. T. O., Seehuus, S.-C., Kim Fondrk, M., Norberg, K., \& Hartfelder, K. (2005). Social reversal of immunosenescence in honey bee workers. Experimental Gerontology ,40 (12), 939-947. doi: 10.1016/j.exger.2005.08.004

Amdam, Gro V., Norberg, K., Fondrk, M. K., \& Page, R. E. (2004). Reproductive ground plan may mediate colony-level selection effects on individual foraging behavior in honey bees. Proceedings of the National Academy of Sciences , 101 (31), 11350-11355. doi: 10.1073/pnas.0403073101

Amdam, Gro V., Simões, Z. L. P., Hagen, A., Norberg, K., Schrøder, K., Mikkelsen, Ø., ... Omholt, S. W. (2004). Hormonal control of the yolk precursor vitellogenin regulates immune function and longevity in honeybees. Experimental Gerontology , 39 (5), 767-773. doi: 10.1016/j.exger.2004.02.010

Ament, S. A., Corona, M., Pollock, H. S., \& Robinson, G. E. (2008). Insulin signaling is involved in the regulation of worker division of labor in honey bee colonies. Proceedings of the National Academy of Sciences , 105 (11), 4226-4231. doi: 10.1073/pnas.0800630105

Anderson, K. E., \& Ricigliano, V. A. (2017). Honey bee gut dysbiosis: a novel context of disease ecology. Current Opinion in Insect Science, 22 , 125-132. doi: 10.1016/j.cois.2017.05.020

Anderson, K. E., Ricigliano, V. A., Mott, B. M., Copeland, D. C., Floyd, A. S., \& Maes, P. (2018). The queen's gut refines with age : longevity phenotypes in a social insect model. Microbiome , 6 (108), 1-16.

Anderson, K. E., Rodrigues, P. A. P., Mott, B. M., Maes, P., \& Corby-Harris, V. (2016). Ecological Succession in the Honey Bee Gut: Shift in Lactobacillus Strain Dominance During Early Adult Development.Microbial Ecology , 71 (4), 1008-1019. doi: 10.1007/s00248-015-0716-2

Ben-Shahar, Y., Robichon, A., Sokolowski, M. B., \& Robinson, G. E. (2002). Influence of gene action across different time scales on behavior. Science, 296 (5568), 741-744. doi: 10.1126/science.1069911 
Burritt, N. L., Foss, N. J., Neeno-Eckwall, E. C., Church, J. O., Hilger, A. M., Hildebrand, J. A., .. B Burritt, J. B. (2016). Sepsis and hemocyte loss in honey bees (Apis mellifera) Infected with serratia marcescens strain sicaria. PLoS ONE , 11 (12), 1-26. doi: 10.1371/journal.pone.0167752

Cervoni, M. S., Cardoso-Junior, C. A. M., Craveiro, G., Souza, A. de O., Alberici, L. C., \& Hartfelder, K. (2017). Mitochondrial capacity, oxidative damage and hypoxia gene expression are associated with agerelated division of labor in honey bee, Apis mellifera L., workers. Journal of Experimental Biology , 220 (21), 4035-4046. doi: 10.1242/jeb.161844

Chang, L.-H., Barron, A. B., \& Cheng, K. (2015). Effects of the juvenile hormone analogue methoprene on rate of behavioural development, foraging performance and navigation in honey bees ( Apis mellifera ).Journal of Experimental Biology , 218 (11), 1715-1724. doi: 10.1242/jeb.119198

Chong, J., Liu, P., Zhou, G., \& Xia, J. (2020). Using MicrobiomeAnalyst for comprehensive statistical, functional, and meta-analysis of microbiome data. Nature Protocols , 15 (3), 799-821. doi: 10.1038/s41596019-0264-1

Cintra-Socolowski, P., Nocelli, R., Roat, T., Silva-Zacarin, E., \& Malaspina, O. (2016). Comparative physiology of Malpighian tubules: form and function. Open Access Insect Physiology , 13. doi: 10.2147/OAIP.S72060

Cohen, E., Sawyer, J. K., Peterson, N. G., Dow, J. A. T., \& Fox, D. T. (2020). Physiology, Development, and Disease Modeling in the Drosophila Excretory System. Genetics , 214 (2), 235-264. doi: 10.1534/genetics.119.302289

Comas, M., \& Thio-Henestrosa, S. (2011). CoDaPack 2.0: a stand-alone, multi-platform compositional software. Proceedings of the 4th International Workshop on Compositional Data Analysis , 1-10.

Corby-Harris, V., Maes, P., \& Anderson, K. E. (2014). The Bacterial Communities Associated with Honey Bee (Apis mellifera) Foragers.PLoS ONE , 9 (4), e95056. doi: 10.1371/journal.pone.0095056

Corona, M., Hughes, K. A., Weaver, D. B., \& Robinson, G. E. (2005). Gene expression patterns associated with queen honey bee longevity.Mechanisms of Ageing and Development , 126 (11), 1230-1238. doi: 10.1016/j.mad.2005.07.004

Dalenberg, H., Maes, P., Mott, B., Anderson, K. E., \& Spivak, M. (2020). Propolis Envelope Promotes Beneficial Bacteria in the Honey Bee (Apis mellifera) Mouthpart Microbiome. Insects , 11 (7), 453. doi: 10.3390/insects11070453

Dukas, R. (2008). Mortality rates of honey bees in the wild.Insectes Sociaux , 55 (3), 252-255. doi: 10.1007/s00040-008-0995-4

Edgar, R. C., Haas, B. J., Clemente, J. C., Quince, C., \& Knight, R. (2011). UCHIME improves sensitivity and speed of chimera detection.Bioinformatics , 27 (16), 2194-2200. doi: 10.1093/bioinformatics/btr381

Engel, P., Anderson, K. E., Cornman, R. S., Dainat, J., Miranda, J. R. De, Doublet, V., ... Schwarz, R. S. (2016). The bee microbiome: Impact on bee health and model for evolution and ecology of host-microbe interactions. MBio , 7 (2), 1-9. doi: 10.1128/mBio.02164-15.Invited

Engel, P., \& Moran, N. A. (2013a). Functional and evolutionary insights into the simple yet specific gut microbiota of the honey bee from metagenomic analysis. Gut Microbes , 4 (1), 60-65. doi: 10.4161/gmic.22517

Engel, P., \& Moran, N. A. (2013b). The gut microbiota of insects - diversity in structure and function. FEMS Microbiology Reviews ,37 (5), 699-735. doi: 10.1111/1574-6976.12025

Evans, J. D., Schwarz, R. S., Chen, Y. P., Budge, G., Cornman, R. S., De la Rua, P., .. Pinto, M. A. (2013). Standard methods for molecular research in Apis mellifera. Journal of Apicultural Research ,52 (4), 1-54. doi: 10.3896/IBRA.1.52.4.11 
Fewell, J. H. (2003). Social Insect Networks. Science,301 (5641), 1867-1870. doi: 10.1126/science.1088945 Fluri, P., Luscher, M., Wille, H., \& Gerig, L. (1982). Changes in weight of the pharyngeal gland and haemolymph titres of juvenile hormone, protein and vitellogenin in worker honey bees. Journal of Insect Physiology , 28 (1), 61-68. doi: 10.1016/0022-1910(82)90023-3

Gloor, G. B., \& Reid, G. (2016). Compositional analysis: A valid approach to analyze microbiome highthroughput sequencing data.Canadian Journal of Microbiology ,62 (8), 692-703. doi: 10.1139/cjm-20150821

Graveley, B. R., Kaur, A., Gunning, D., Zipursky, S. L., Rowen, L., \& Clemens, J. C. (2004). The organization and evolution of the Dipteran and Hymenopteran Down syndrome cell adhesion molecule ( Dscam ) genes.RNA , 10 (10), 1499-1506. doi: 10.1261/rna.7105504

Harman, D. (1956). Aging: A Theory Based on Free Radical and Radiation Chemistry. Journal of Gerontology , 11 (3), 298-300. doi: 10.1093/geronj/11.3.298

Harwood, G., \& Amdam, G. (2021). Vitellogenin in the honey bee midgut.Apidologie, 52 (4), 837-847. doi: $10.1007 / \mathrm{s} 13592-021-00869-3$

Holldobler, B., \& Wilson, E. O. (2008). The Superorganism: The Beauty, Elegance, and Strangeness of Insect Societies (1st ed.). W. W. Norton \& Company. doi: 10.1111/j.1748-1716.1958.tb01719.x

Hsieh, Y.-S., \& Hsu, C.-Y. (2011). Honeybee trophocytes and fat cells as target cells for cellular senescence studies. Experimental Gerontology , 46 (4), 233-240. doi: 10.1016/j.exger.2010.10.007

Huang, Z.-Y., \& Robinson, G. E. (1996). Regulation of Honey Bee Division of Labor by Colony Age Demography. Behavioral Ecology and Sociobiology , 39 (3), 147-158. Retrieved from https://www.jstor.org/stable/4601247

Huang, Z. Y., \& Robinson, G. E. (1992). Honeybee colony integration: worker-worker interactions mediate hormonally regulated plasticity in division of labor. Proceedings of the National Academy of Sciences , 89 (24), 11726-11729. doi: 10.1073/pnas.89.24.11726

Institute, S. A. S. (2015). Base SAS 9.4 Procedures Guide, Fifth Edition, 5th Edition. SAS Institute.

Jones, J. C., Fruciano, C., Marchant, J., Hildebrand, F., Forslund, S., Bork, P., .. Hughes, W. O. H. (2018). The gut microbiome is associated with behavioural task in honey bees. Insectes Sociaux ,65 (3), 419-429. doi: 10.1007/s00040-018-0624-9

Kapheim, K. M., Rao, V. D., Yeoman, C. J., Wilson, B. A., White, B. A., Goldenfeld, N., \& Robinson, G. E. (2015). Caste-specific differences in hindgut microbial communities of honey bees (Apis mellifera). PLoS ONE , 10 (4), 1-14. doi: 10.1371/journal.pone.0123911

Kešnerová, L., Emery, O., Troilo, M., Liberti, J., Erkosar, B., \& Engel, P. (2020). Gut microbiota structure differs between honeybees in winter and summer. The ISME Journal , 14 (3), 801-814. doi: 10.1038/s41396019-0568-8

Kešnerová, L., Mars, R. A. T., Ellegaard, K. M., Troilo, M., Sauer, U., \& Engel, P. (2017). Disentangling metabolic functions of bacteria in the honey bee gut . doi: 10.1101/157461

Kwong, W. K., Mancenido, A. L., \& Moran, N. A. (2017). Immune system stimulation by the native gut microbiota of honey bees. Royal Society Open Science , 4 (2), 170003. doi: 10.1098/rsos.170003

Kwong, W. K., \& Moran, N. A. (2016). Gut microbial communities of social bees. Nature Reviews Microbiology , 14 (6), 374-384. doi: 10.1038/nrmicro.2016.43

Lei, X. G., Zhu, J.-H., Cheng, W.-H., Bao, Y., Ho, Y.-S., Reddi, A. R., .. Arnér, E. S. J. (2016). Paradoxical Roles of Antioxidant Enzymes: Basic Mechanisms and Health Implications. Physiological Reviews , 96 (1), 307-364. doi: 10.1152/physrev.00010.2014 
Liu, C. M., Aziz, M., Kachur, S., Hsueh, P. R., Huang, Y. T., Keim, P., \& Price, L. B. (2012). BactQuant: an enhanced broad-coverage bacterial quantitative real-time PCR assay. BMC Microbiology , 12 . doi: 10.1186/1471-2180-12-56

Liu, C. M., Kachur, S., Dwan, M. G., Abraham, A. G., Aziz, M., Hsueh, P.-R., .. Price, L. B. (2012). FungiQuant: A broad-coverage fungal quantitative real-time PCR assay. BMC Microbiology , 12 (1), 255. doi: $10.1186 / 1471-2180-12-255$

Liu, Y., Liu, H., Liu, S., Wang, S., Jiang, R.-J., \& Li, S. (2009). Hormonal and nutritional regulation of insect fat body development and function. Archives of Insect Biochemistry and Physiology ,71 (1), 16-30. doi: 10.1002/arch.20290

Livak, K. J., \& Schmittgen, T. D. (2001). Analysis of relative gene expression data using real-time quantitative PCR and the 2- $\Delta \Delta$ CT method.Methods , 25 (4), 402-408. doi: 10.1006/meth.2001.1262

Lourenço, A. P., Martins, J. R., Torres, F. A. S., Mackert, A., Aguiar, L. R., Hartfelder, K., ... Simões, Z. L. P. (2019). Immunosenescence in honey bees (Apis mellifera L.) is caused by intrinsic senescence and behavioral physiology. Experimental Gerontology , 119 (February), 174-183. doi: 10.1016/j.exger.2019.02.005

Ludvigsen, J., Andersen, Å., Hjeljord, L., \& Rudi, K. (2020). The Honeybee Gut Mycobiota Cluster by Season versus the Microbiota which Cluster by Gut Segment. Veterinary Sciences , 8 (1), 4. doi: 10.3390/vetsci8010004

Ludvigsen, J., Rangberg, A., Avershina, E., Sekelja, M., Kreibich, C., Amdam, G., \& Rudi, K. (2015). Shifts in the Midgut/Pyloric Microbiota Composition within a Honey Bee Apiary throughout a Season.Microbes and Environments , 30 (3), 235-244. doi: 10.1264/jsme2.ME15019

Maes, P. W., Floyd, A. S., Mott, B. M., \& Anderson, K. E. (2021). Overwintering Honey Bee Colonies: Effect of Worker Age and Climate on the Hindgut Microbiota. Insects , 12 (3), 224. doi: 10.3390/insects12030224

Maes, P. W., Rodrigues, P. A. P., Oliver, R., Mott, B. M., \& Anderson, K. E. (2016). Diet-related gut bacterial dysbiosis correlates with impaired development, increased mortality and Nosema disease in the honeybee (Apis mellifera). Molecular Ecology , 25 (21), 5439-5450. doi: 10.1111/mec.13862

Marco Antonio, D. S., Guidugli-Lazzarini, K. R., Do Nascimento, A. M., Simões, Z. L. P., \& Hartfelder, K. (2008). RNAi-mediated silencing of vitellogenin gene function turns honeybee (Apis mellifera) workers into extremely precocious foragers. Naturwissenschaften ,95 (10), 953-961. doi: 10.1007/s00114-008-0413-9

Martinson, V. G., Moy, J., \& Moran, N. A. (2012). Establishment of Characteristic Gut Bacteria during Development of the Honeybee Worker.Applied and Environmental Microbiology , 78 (8), 2830-2840. doi: 10.1128/aem.07810-11

Nelson, C. M., Ihle, K. E., Fondrk, M. K., Page, R. E., \& Amdam, G. V. (2007). The Gene vitellogenin Has Multiple Coordinating Effects on Social Organization. PLoS Biology , 5 (3), e62. doi: 10.1371/journal.pbio.0050062

Oster, G. F., \& Wilson, E. O. (1978). Caste and ecology in the social insects (E. O. Wilson, ed.). Princeton, N.J.: Princeton, N.J. : Princeton University Press.

Pankiw, T. (2004). Worker honey bee pheromone regulation of foraging ontogeny. Naturwissenschaften , 91 (4), 178-181. doi: 10.1007/s00114-004-0506-z

Pearson, K. (1897). Mathematical contributions to the theory of evolution. - On a form of spurious correlation which may arise when indices are used in the measurement of organs. Proceedings of the Royal Society of London , 60 (359-367), 489-498. doi: 10.1098/rspl.1896.0076

Perry, C. J., Sovik, E., Myerscough, M. R., \& Barron, A. B. (2015). Rapid behavioral maturation accelerates failure of stressed honey bee colonies. Proceedings of the National Academy of Sciences ,112 (11), 3427-3432. doi: $10.1073 /$ pnas. 1422089112 
Powell, J. E., Carver, Z., Leonard, S. P., \& Moran, N. A. (2021). Field-Realistic Tylosin Exposure Impacts Honey Bee Microbiota and Pathogen Susceptibility, Which Is Ameliorated by Native Gut Probiotics.Microbiology Spectrum , 9 (1). doi: 10.1128/Spectrum.00103-21

Prado, A., Requier, F., Crauser, D., Le Conte, Y., Bretagnolle, V., \& Alaux, C. (2020). Honeybee lifespan: the critical role of pre-foraging stage. Royal Society Open Science, 7 (11), 200998. doi: 10.1098/rsos.200998

Raymann, K., Coon, K. L., Shaffer, Z., Salisbury, S., \& Moran, N. A. (2019). Pathogenicity of Serratia marcescens Strains in Honey Bees.Microbiology Spectrum , 7 (4), 1-16. doi: 10.1128/microbiolspec.gpp30053-2018

Raymann, K., Shaffer, Z., \& Moran, N. A. (2017). Antibiotic exposure perturbs the gut microbiota and elevates mortality in honeybees.PLOS Biology . doi: 10.1371/journal.pbio.2001861

Remolina, S. C., Hafez, D. M., Robinson, G. E., \& Hughes, K. A. (2007). Senescence in the worker honey bee Apis Mellifera. Journal of Insect Physiology , 53 (10), 1027-1033. doi: 10.1016/j.jinsphys.2007.05.015

Reznick, A. Z., \& Packer, L. (1994). Oxidative damage to proteins: Spectrophotometric method for carbonyl assay. Methods in Enzymology , 233 (C), 357-363. doi: 10.1016/S0076-6879(94)33041-7

Ricigliano, V. A., Fitz, W., Copeland, D. C., Mott, B. M., Maes, P., Floyd, A. S., . . Anderson, K. E. (2017). The impact of pollen consumption on honey bee ( Apis mellifera ) digestive physiology and carbohydrate metabolism. Archives of Insect Biochemistry and Physiology , 96 (2), 1-14. doi: 10.1002/arch.21406

Robinson, G. E. (1992). Regulation of Division of Labor in Insect Societies. Annual Review of Entomology , 37 (1), 637-665. doi: 10.1146/annurev.en.37.010192.003225

Robinson, G. E., Page, R. E., Strambi, C., \& Strambi, A. (1989). Hormonal and Genetic Control of Behavioral Integration in Honey Bee Colonies. Science, 246 (4926), 109-112. doi: 10.1126/science.246.4926.109

Rokop, Z. P., Horton, M. A., \& Newton, I. L. G. (2015). Interactions between Cooccurring Lactic Acid Bacteria in Honey Bee Hives.Applied and Environmental Microbiology , 81 (20), 7261-7270. doi: 10.1128/AEM.01259-15

Rueppell, O., Christine, S., Mulcrone, C., \& Groves, L. (2007). Aging without functional senescence in honey bee workers. Current Biology , 17 (8), R274-R275. doi: 10.1016/j.cub.2007.02.015

Sabree, Z. L., Hansen, A. K., \& Moran, N. A. (2012). Independent studies using deep sequencing resolve the same set of core bacterial species dominating gut communities of honey bees. PLoS ONE,7 (7). doi: 10.1371/journal.pone.0041250

Schloss, P. D., Westcott, S. L., Ryabin, T., Hall, J. R., Hartmann, M., Hollister, E. B., .. Weber, C. F. (2009). Introducing mothur : Open-Source, Platform-Independent, Community-Supported Software for Describing and Comparing Microbial Communities ?. Applied and Environmental Microbiology , 75 (23), 7537-7541. doi: 10.1128/AEM.01541-09

Schmid, M. R., Brockmann, A., Pirk, C. W. W., Stanley, D. W., \& Tautz, J. (2008). Adult honeybees (Apis mellifera L.) abandon hemocytic, but not phenoloxidase-based immunity. Journal of Insect Physiology ,54 (2), 439-444. doi: 10.1016/j.jinsphys.2007.11.002

Seehuus, S.-C., Norberg, K., Gimsa, U., Krekling, T., \& Amdam, G. V. (2006). Reproductive protein protects functionally sterile honey bee workers from oxidative stress. Proceedings of the National Academy of Sciences , 103 (4), 962-967. doi: 10.1073/pnas.0502681103

Seehuus, Siri-Christine, Norberg, K., Krekling, T., Fondrk, K., \& Amdam, G. V. (2007). Immunogold Localization of Vitellogenin in the Ovaries, Hypopharyngeal Glands and Head Fat Bodies of Honeybee Workers, Apis Mellifera. Journal of Insect Science, 7 (52), 1-14. doi: 10.1673/031.007.5201 
Seeley, T. D. (1982). Adaptive significance of the age polyethism schedule in honeybee colonies. Behavioral Ecology and Sociobiology , 11 (4), 287-293. doi: 10.1007/BF00299306

Smith, P. K., Krohn, R. I., Hermanson, G. T., Mallia, A. K., Gartner, F. H., Provenzano, M. D., ... Klenk, D. C. (1985). Measurement of protein using bicinchoninic acid. Analytical Biochemistry ,150 (1), 76-85. doi: 10.1016/0003-2697(85)90442-7

Steele, M. I., Kwong, W. K., Whiteley, M., \& Moran, N. A. (2017). Diversification of Type VI Secretion System Toxins Reveals Ancient Antagonism among Bee Gut Microbes. MBio , 8 (6), 1-19. doi: 10.1128/mBio.01630-17

Stoddard, S. F., Smith, B. J., Hein, R., Roller, B. R. K., \& Schmidt, T. M. (2015). rrnDB: Improved tools for interpreting rRNA gene abundance in bacteria and archaea and a new foundation for future development.Nucleic Acids Research , 43 (D1), D593-D598. doi: 10.1093/nar/gku1201

Toth, A. L., \& Robinson, G. E. (2005). Worker nutrition and division of labour in honeybees. Animal Behaviour , 69 (2), 427-435. doi: 10.1016/j.anbehav.2004.03.017

Vance, J. T., Williams, J. B., Elekonich, M. M., \& Roberts, S. R. (2009). The effects of age and behavioral development on honey bee (Apis mellifera) flight performance. Journal of Experimental Biology ,212 (16), 2604-2611. doi: 10.1242/jeb.028100

Vannette, R. L., Mohamed, A., \& Johnson, B. R. (2015). Forager bees (Apis mellifera) highly express immune and detoxification genes in tissues associated with nectar processing. Scientific Reports ,5 (1), 16224. doi: $10.1038 /$ srep16224

Visscher, P. K., \& Dukas, R. (1997). Survivorship of foraging honey bees. Insectes Sociaux , 44 (1), 1-5. doi: $10.1007 / \mathrm{s} 000400050017$

Vonaesch, P., Anderson, M., \& Sansonetti, P. J. (2018). Pathogens, microbiome and the host: Emergence of the ecological Koch's postulates.FEMS Microbiology Reviews , 42 (3), 273-292. doi: 10.1093/femsre/fuy003

Wang, Q., Garrity, G. M., Tiedje, J. M., \& Cole, J. R. (2007). Naïve Bayesian classifier for rapid assignment of rRNA sequences into the new bacterial taxonomy. Applied and Environmental Microbiology ,73 (16), 5261-5267. doi: 10.1128/AEM.00062-07

Watson, F. L., Watson, F. L., Pu, R., Kondo, M., Rebel, V. I., \& Schmucker, D. (2005). Extensive Diversity of Ig-Superfamily Proteins in the Immune System of Insects. Science , 309 (September), 1874-1878. doi: $10.1126 /$ science. 1116887

Williams, J. B., Roberts, S. P., \& Elekonich, M. M. (2008). Age and natural metabolically-intensive behavior affect oxidative stress and antioxidant mechanisms. Experimental Gerontology , 43 (6), 538-549. doi: 10.1016/j.exger.2008.02.001

Wilson-Rich, N., Dres, S. T., \& Starks, P. T. (2008). The ontogeny of immunity: Development of innate immune strength in the honey bee (Apis mellifera). Journal of Insect Physiology , 54 (10-11), 1392-1399. doi: $10.1016 /$ j.jinsphys.2008.07.016

Zheng, H., Nishida, A., Kwong, W. K., Koch, H., Engel, P., Steele, M. I., \& Moran, N. A. (2016). Metabolism of Toxic Sugars by Strains of the Bee Gut Symbiont Gilliamella apicola . MBio , 7 (6), e01326-16. doi: 10.1128/mBio.01326-16

Zheng, H., Powell, J. E., Steele, M. I., Dietrich, C., \& Moran, N. A. (2017). Honeybee gut microbiota promotes host weight gain via bacterial metabolism and hormonal signaling. Proceedings of the National Academy of Sciences . doi: 10.1073/pnas.1701819114

\section{DATA ACCESSIBILITY}

The sequence data for this study have been deposited in GenBank, Sequence Read Archive no. PRJNA801240. 


\section{BENEFIT-SHARING STATEMENT}

Benefits from this research accrue from the sharing of our data and results on public databases as described above.

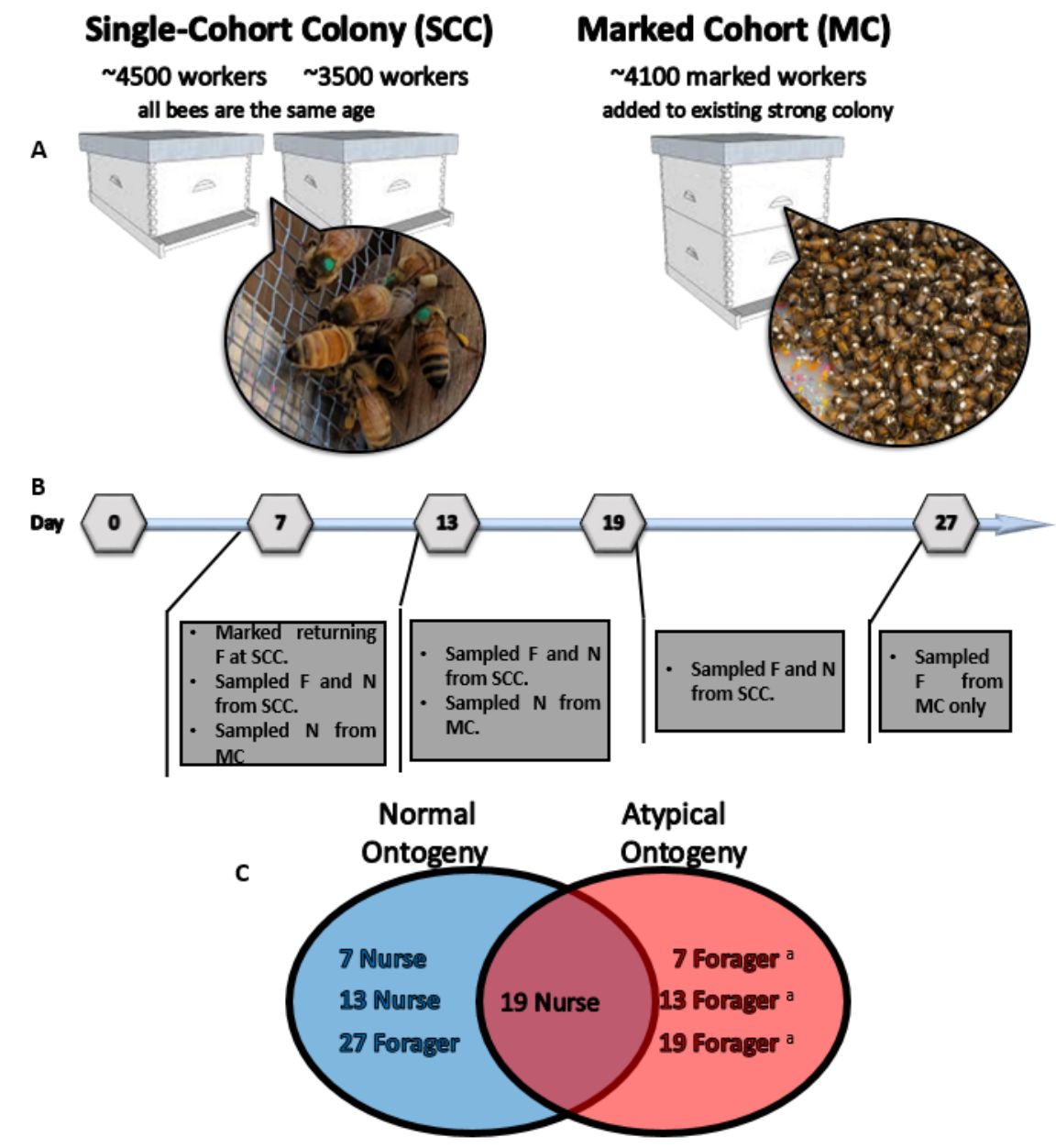

Figure 1. Experimental design. A) To decouple age and behavioral task, we created two single-cohort colonies (SCC) with 4500 and 3500 bees. In a SCC, all bees are the same age and a proportion will differentiate into precocious foragers. We also established a marked cohort to sample normal age bees following classic ontogeny patterns. B) F = Forager, $\mathrm{N}=$ Nurse. Sampling occurred at day 7, 13, 19, and 27. C) Normal (ageright) ontogeny occurs under normal colony demography. Atypical represented by ${ }^{\mathrm{a}}$, designates a decoupling of age and behavior in response to colony needs. 19-day nurses are neither normal nor atypical, but represent an overage nurse or nurse that will soon transition into foraging. 


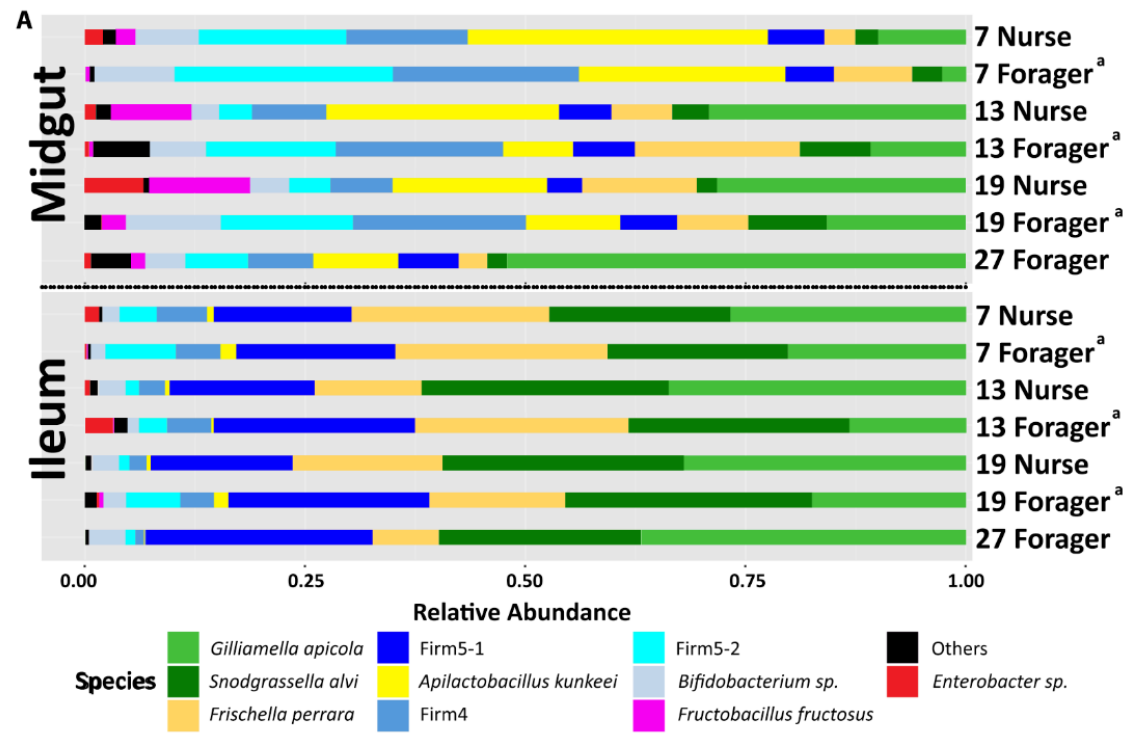

\section{B Midgut}

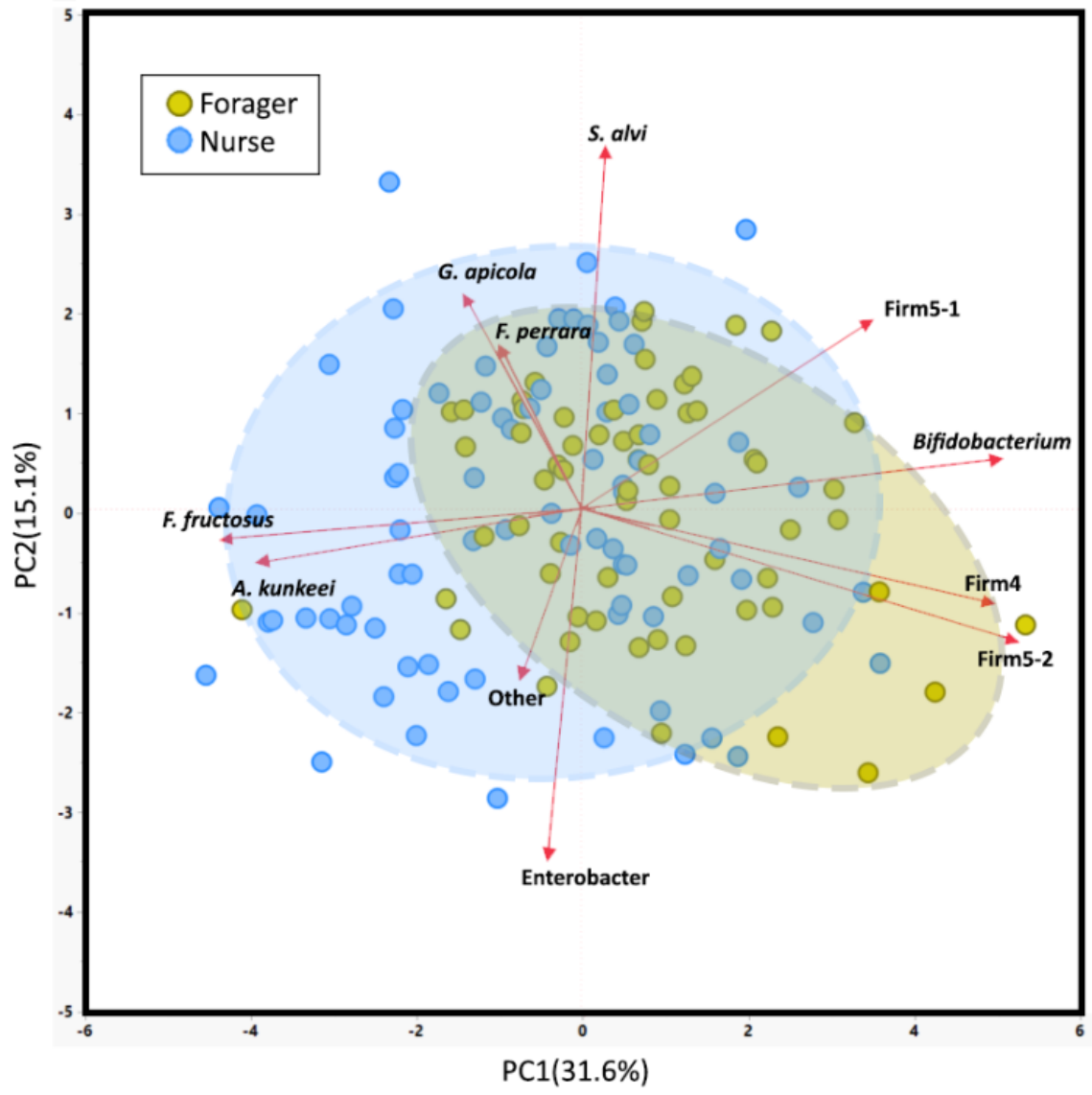




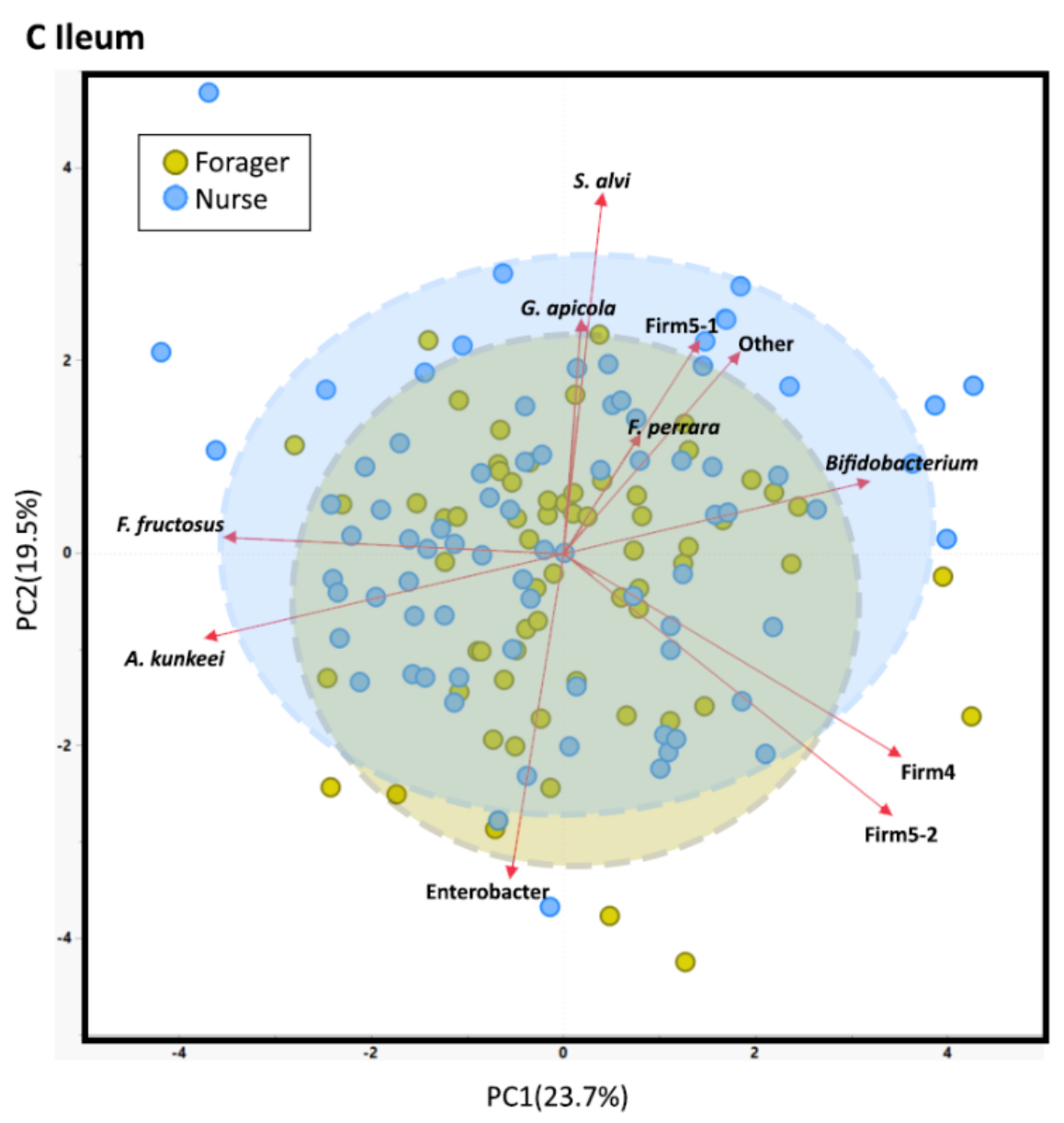

Figure 2. A) The honey bee microbiota of the midgut and ileum. Color-coded bars represent relative abundance corrected by species-specific $16 \mathrm{~S}$ rRNA gene copy number. Black represents diversity abundance, OTU's 11-1230. B and C) Principal component analysis of the midgut and Ileum respectively based on the most abundant OTUs. Clustered groups of points contain similar groupings of taxa with similar ratio abundances, and longer OTU vectors result from greater variation in CLR scores.

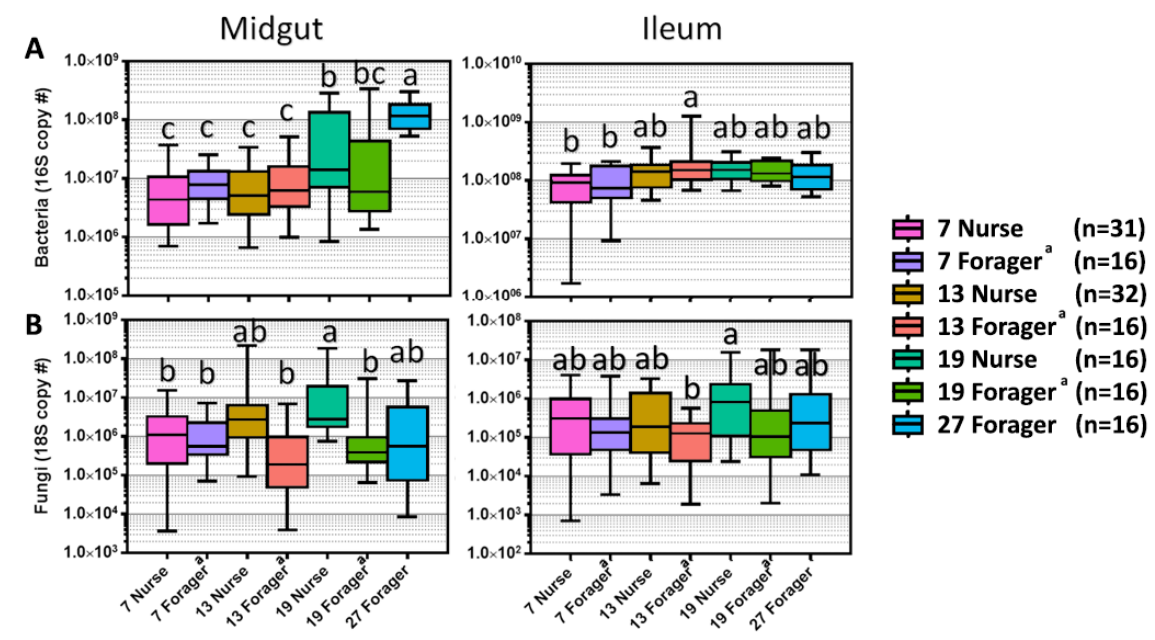


Figure 3. A) Box and whisker plots representing total bacterial abundance in midgut and ileum tissues. B) Box and whisker plots representing total fungal abundance in midgut and ileum tissues. The y-axis is logarithmic scale $(\log 10)$. Different letters indicate significant differences at $\mathrm{p}<0.05$. Atypical age/behavioral task represented by ${ }^{a}$
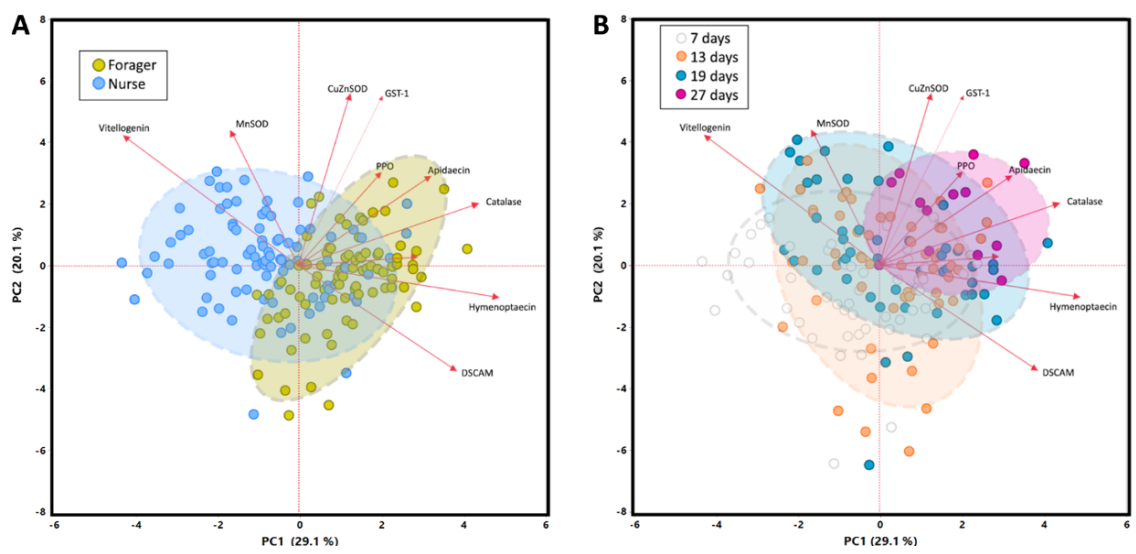

Figure 4. Principal component analysis of fatbody gene expression by both age (A) and task (B).

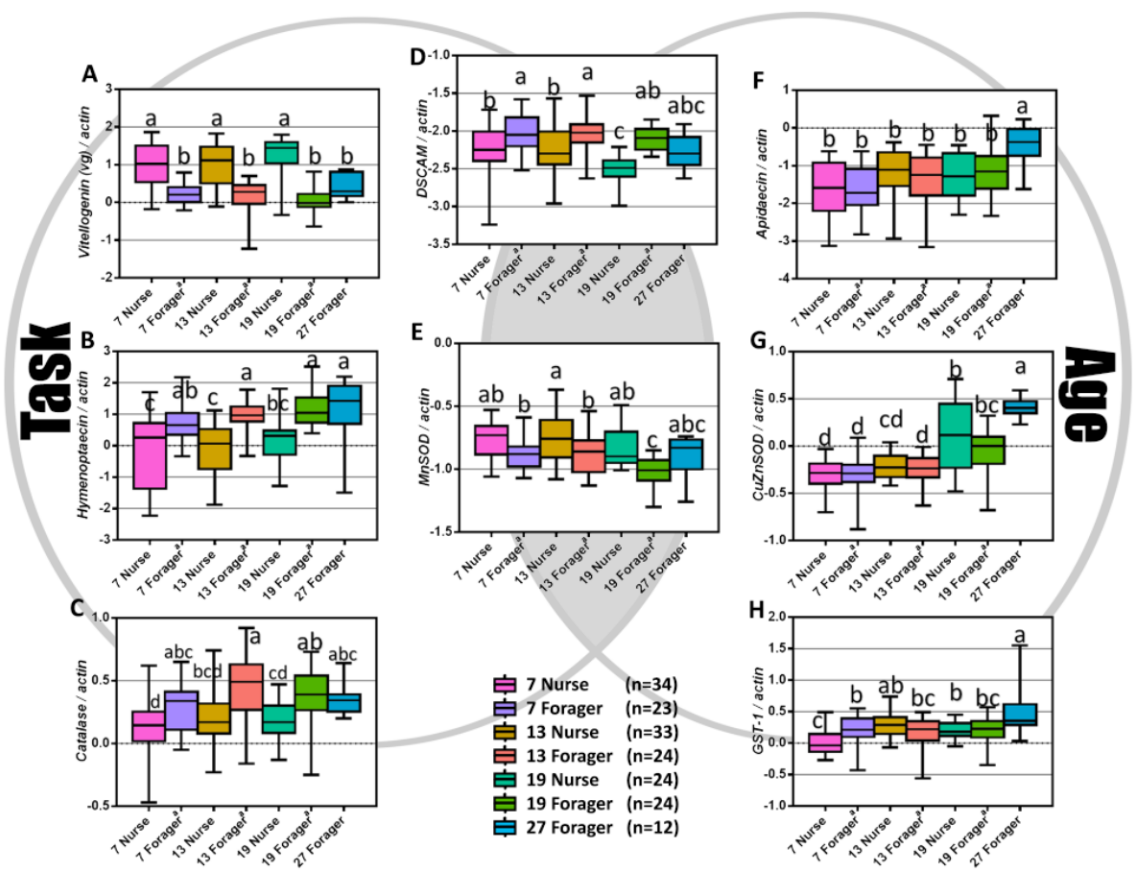

Figure 5. A-C: The background indicates gene expression can fall into patterns of task, age, or an interaction of the two. Gene expression is relative to actin. Vitellogenin, hymenoptaecin, and catalase expression regulated by task. D-E: DSCAM and MnSOD expression is explained by both task and age. F-H: Apidaecin, CuZnSOD, and GST-1 expression increased with age. Different letters indicate significant differences $(\mathrm{p}<$ 0.05). Atypical age/behavioral task represented by ${ }^{a}$ 


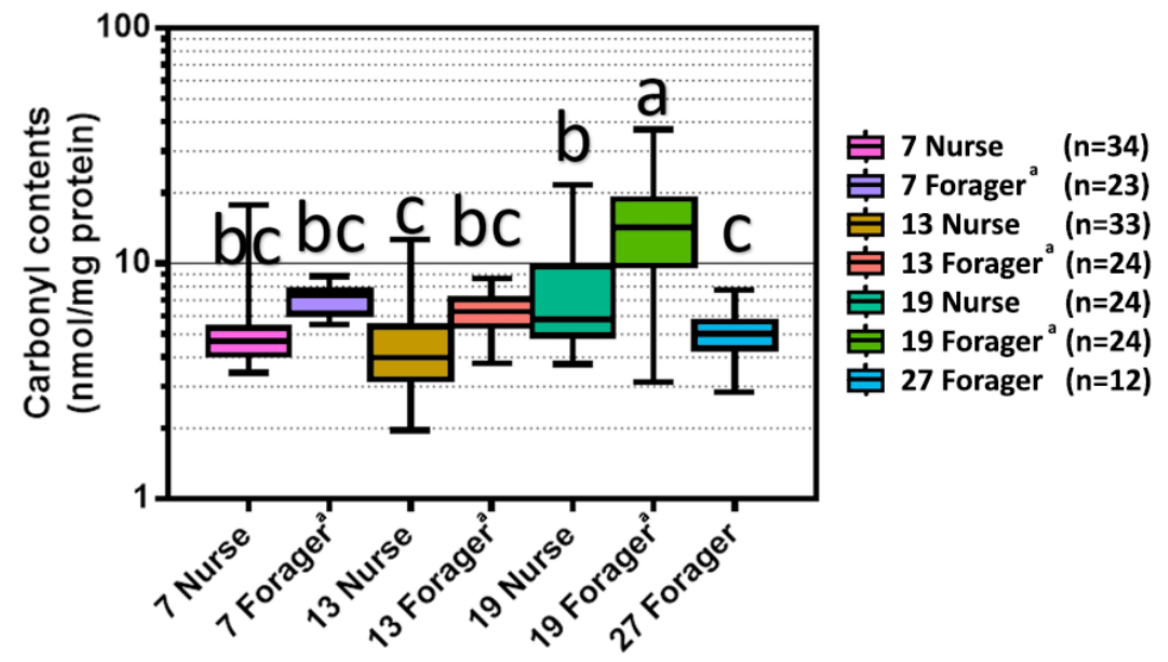

Figure 6. Protein oxidation of the abdomen measured by carbonylation. Different letters indicate significant differences $(\mathrm{p}<0.05)$. Atypical age/behavioral task represented by ${ }^{a}$

Table 1. Two-way MANOVA results of microbiotas from the midgut and Ileum.

\section{Hosted file}

image9.emf available at https://authorea.com/users/462355/articles/557806-social-structureaffects-the-gut-microbiota-in-honey-bees-the-physiological-cost-of-precocious-foraging 